\title{
Case Report \\ Rhabdomyolysis and Acute Kidney Injury due to Severe Heat Stroke
}

\author{
Máximo H. Trujillo ${ }^{1,2}$ and Carlos Fragachán G..$^{1,2}$ \\ ${ }^{1}$ Critical Care Department, ICU, Instituto Médico La Floresta (IMLF), Caracas 1060, Venezuela \\ ${ }^{2}$ Critical Care Department, University Hospital of Caracas, Caracas 1050, Venezuela
}

Correspondence should be addressed to Máximo H. Trujillo, maximotrujillo@gmail.com

Received 8 August 2011; Accepted 18 September 2011

Academic Editor: F. Mariano

Copyright () 2011 M. H. Trujillo and C. Fragachán G. This is an open access article distributed under the Creative Commons Attribution License, which permits unrestricted use, distribution, and reproduction in any medium, provided the original work is properly cited.

We present a case of heat stroke (HS) and acute kidney injury (AKI) due to severe rhabdomyolysis in a 14-year-old previously healthy female patient. When she was practicing strenuous exercise she suffered acute seizures and high fever. These symptoms were followed by coma and multiple organ failure (MOF), which included AKI, encephalopathy, fulminant hepatic failure (FHF), and disseminated intravascular coagulation (DIC). The patient was managed in the ICU with renal replacement therapy, ventilatory support, and other vital supporting measures. After three weeks of ICU treatment she made a full recovery.

\section{Introduction}

Rhabdomyolysis is a syndrome characterized by the leakage of muscle-cell contents into the circulation. Strenuous exercise and HS are the most common causes of rhabdomyolysis. The severity of illness ranges from asymptomatic elevations of the serum levels of muscle enzymes to life-threatening cases associated with extreme elevations of creatine kinase (CK) and liver enzymes (ALT, AST), electrolyte imbalances, and AKI. There are two forms of rhabdomyolysis: traumatic, often resulting from crush injuries and extensive trauma sustained in natural disasters and wars and nontraumatic, which include, among other causes, excessive physical exertion, HS, exogenous toxins, usage of illicit drugs, malignant hyperthermia, alcohol, and prescription medications. The risk of AKI in rhabdomyolisis is usually low when CK levels on admission are less than $20000 \mathrm{U} / \mathrm{L}$. Nevertheless, AKI is still at risk with values of CK as low as $5000 \mathrm{U} / \mathrm{L}$ when other coexisting conditions occurs such as sepsis, severe dehydration, and acidosis [1-4]. In addition to rhabdomyolisis, all three risk factors may coexist in severe HS. Usually the cause of rhabdomyolysis is evident from the patient's history or from circumstances immediately preceding the disorder, and only occasionally the precipitant cause will not be obvious.
The classic presentation of rhabdomyolysis includes myalgias, limb weakness, and pigmenturia due to myoglobinuria without hematuria. AKI is a potential complication of severe rhabdomyolysis independently of its etiology, which accounts for $8-15 \%$ of all cases of AKI in the US. The mortality rate of HS can be as high as $70 \%$, especially when treatment is delayed, and the presence of MOF [59]. Elevated serum creatinine and oliguria associated with rhabdomyolysis and coagulopathy in HS further increase the rate of AKI and mortality [8].

\section{Report of the Case}

On admission to the ICU her physical examination revealed a temperature of $38^{\circ} \mathrm{C}$, blood pressure of $160 / 90 \mathrm{mmHg}$, pulse rate of $150 / \mathrm{min}$, and respiratory rate of $35 / \mathrm{min}$. Oxygen saturation was $90 \%$. Except for dry mucous membranes, the rest of her physical examination was unremarkable. Soon after admission to the ICU she became unconscious, requiring tracheal intubation and ventilatory support. A chest X-ray and EKG were normal. A cerebral CT scan revealed mild cerebral edema in both hemispheres.

Laboratory testing revealed serum creatinine $2.4 \mathrm{mg} / \mathrm{dL}$, blood urea nitrogen (BUN) $104 \mathrm{mg} / \mathrm{dL}$, potassium $3 \mathrm{mEq} / \mathrm{L}$, 
sodium $150 \mathrm{mEq} / \mathrm{L}$, CPK level 24,385 U/L, serum myoglobin $>3000 \mathrm{ng} / \mathrm{mL}$, total bilirubin $3.12 \mathrm{mg} / \mathrm{dL}$ (d/i: 1.49/1.71), ALAT $382 \mathrm{U} / \mathrm{L}$ and AST of $282 \mathrm{U} / \mathrm{L}$, and LDH of $1,376 \mathrm{U} / \mathrm{L}$; serum ammonium $16 \mathrm{mmol} / \mathrm{L}$ (reference values 10$80 \mathrm{mmol} / \mathrm{L}$ ); INR 2.73, and serum fibrinogen of $203 \mathrm{mg} / \mathrm{dL}$. The urinalysis revealed reddish brown urine highly positive for myoglobin. The diagnosis of severe exertional HS and rhabdomyolysis with ensuing AKI was established. The patient received IV hydration, ventilatory support, sodium bicarbonate, corticosteroids, and enteral nutrition. During the next 3 days, her CPK level increased to $36,423 \mathrm{U} / \mathrm{L}$, the serum myoglobin $>3000 \mathrm{ng} / \mathrm{mL}$, ALAT 9,942 U/L, AST $5,910 \mathrm{U} / \mathrm{L}$, and $\mathrm{LDH}$ to $4,623 \mathrm{U} / \mathrm{L}$. Serum ammonium $117 \mathrm{mmol} / \mathrm{L}$, INR 4.7, and the total bilirubin $11.9 \mathrm{mg} / \mathrm{dL}$ (d/i: 9.6/2.3). These last laboratory findings and the onset of encephalopathy and coagulopathy in a patient with not known previous liver disease were consistent with the diagnosis of FHF.

The platelet count decreased to $18,000 / \mathrm{mm}^{3}$, the plasma fibrinogen to $104 \mathrm{mg} / \mathrm{dL}$, and the fibrinogen split products were $20 \mu \mathrm{g} / \mathrm{mL}(<10 \mu \mathrm{g} / \mathrm{mL})$, supporting the diagnosis of DIC without evidence of active bleeding. On the fourth day, the patient became oliguric $(<20 \mathrm{~mL} / \mathrm{h})$ and the serum creatinine increased to $5.6 \mathrm{mg} / \mathrm{dL}$ with BUN of $118 \mathrm{mg} / \mathrm{dL}$. The diagnosis of AKI was definitively established, and daily hemodialysis was started and maintained for 17 days. By the 5 th hospitalization day she had a maximum APACHE II and SAPS scores of 37 and 78 points, respectively. By the 12th day in the ICU, the urine flow started a progressive increase, reaching a maximum of $5 \mathrm{~L} / 24 \mathrm{~h}$. This was accompanied by a decrease of serum creatinine to $2.3 \mathrm{mg} / \mathrm{dL}$ and BUN to $38 \mathrm{mg} / \mathrm{dL}$. Hemodialysis was then discontinued. Simultaneously, serum levels of bilirubin, ammonium, ALAT, AST, $\mathrm{CK}$, and myoglobin showed a progressive decrease to normal values. The patient was weaned from the ventilator and extubated on her 14th day of admission to the ICU. Her CNS involvement improved steadily, and complete recovery was attained by the 25 th day of hospitalization. Further recovery was uneventful, and she was discharged home. After 3 weeks, she returned to school and normal activities.

\section{Discussion}

Two forms of HS have been described: the classic or nonexertional HS, which occurs frequently during environmental heat waves, and exertional HS, which usually occurs in healthy, young, and physically active people who engage in strenuous exercise. Renal dysfunction is a well-documented feature in HS that occurs in 30\% of cases approximately. The etiology is multifactorial, and this includes direct thermal injury, rhabdomyolysis, DIC, and renal hypoperfusion due to volume depletion and arterial hypotension [10-13]. AKI associated with myoglobinuria is the most serious complication of both traumatic and nontraumatic rhabdomyolysis and may be life threatening. AKI as a complication of rhabdomyolysis is quite common, representing about 7-10\% of all cases of AKI in the United States [14], but the incidence of AKI in rhabdomyolysis may be as high as 50\% $[3,4,14]$.
In spite of early volume replacement and correction of transient arterial hypotension, AKI was an early feature in the present case, suggesting that rhabdomyolysis played a central role in the pathophysiology of this complication. Massive rhabdomyolysis may follow strenuous physical exertion, particularly when associated with other risk factors such as extremely hot and humid conditions, poor physical fitness, and hypokalemia $[5,15]$. Apart from severe dehydration and fluid sequestration in injured muscles, AKI in the context of rhabdomyolysis results from a combination of factors. These include direct tubular toxicity, ischemia caused by circulating vasoconstrictors, activation of the sympathetic nervous system, antidiuretic hormone, and the renin-angiotensin system [16]. Myoglobin itself seems to have no marked nephrotoxic effect on the tubules unless the urine is acid. In which case it is reasonable to consider alkalinization of urine as a therapeutic measure, especially in patients with metabolic acidosis $[14,16]$. When serum myoglobin levels reach $100 \mathrm{mg} / \mathrm{dL}$, the urine becomes reddish-brown in color. In establishing a differential diagnosis of myoglobinuria, other causes of pigmenturia should be considered (Table 1).

One of the first steps in managing patients with HS in addition to rapid body cooling is prompt IV repletion of fluids. However, once renal damage supervenes, as occurred with our patient, renal replacement therapy is required to control hyperkalemia, fluid overload, and uremia. The outcome of rhabdomyolysis is usually good provided there is no renal failure. Mortality data vary widely according to severity and coexisting conditions. In cases of rhabdomyolysis secondary to limb ischemia (crush injury) mortality can be as high as $32 \%$ [17], and among patients hospitalized in intensive care units mortality has been reported to be as high as $59 \%$ when AKI is present and $22 \%$ when it is not [18]. In contrast, long-term survival among patients with AKI due to rhabdomyolysis is close to $80 \%$, and the majority of them usually recover full renal function [19].

Liver dysfunction and increased serum levels of liver enzymes are commonly observed in HS, whereas FHF is a rare event FHF, defined as "the onset of encephalopathy and coagulopathy in patients with no known previous liver disease," is very uncommon in HS, and only three reports of such cases have been previously published. Two of them recovered completely with conservative ICU treatment [20, 21]. Our patient also made a full recovery from FHF, suggesting that both liver injury and AKI in exertional HS may be reversible.

The severity and complications of exertional HS correlate with the temperature duration curve, suggesting that a rapid reduction in the core temperature by any cooling method (immersion in iced water, iced peritoneal, or gastric lavage) as early as possible should have a positive effect on prognosis. In fact, this single measure seems to be the most effective way of preventing MOF in HS patients. Unfortunately, the "golden hour" for our patient had probably passed by the time she arrived at the ICU [22]. We believe that had she received rapid cooling measures immediately on admission to the suburban hospital, the extent of organ damage may have been limited. 
TABLE 1: Differential diagnosis of pigmenturia.

\begin{tabular}{|c|c|c|c|c|c|c|}
\hline & Hematuria & Hemoglobinuria & Myoglobinuria & Bile pigments & Porphyria & Alkaptonuria \\
\hline Pigment & $\mathrm{RBC}^{*}$ & Hemoglobin & Myoglobin & Bilirubin/Urobilin & Porphobilinogen & $\begin{array}{c}\text { Homogentisinic } \\
\text { acid }\end{array}$ \\
\hline Urine color & Red & Pink & Red to brown & Brown & $\begin{array}{l}\text { Turns brown, red, } \\
\text { purple or black on } \\
\text { standing at } \\
\text { sunlight. } \\
\text { Fluoresces with UV } \\
\text { light }\end{array}$ & $\begin{array}{l}\text { Turns dark in } \\
\text { alkaline solutions. } \\
\text { Darkens on } \\
\text { standing at } \\
\text { sunlight. }\end{array}$ \\
\hline $\begin{array}{l}\text { Urine } \\
\text { Sedi-ment*** }\end{array}$ & $\begin{array}{l}\mathrm{RBC} \text { and } \mathrm{RBC} \\
\text { casts }\end{array}$ & Normal $^{* *}$ & Normal & Normal & Normal & Normal \\
\hline $\begin{array}{l}\text { Supernatant urine } \\
\text { color }\end{array}$ & Yellow & Red to brown & Red to brown & Brown & $\begin{array}{c}\text { Red. } \\
\text { (Watson-Schwartz } \\
\text { test positive) }\end{array}$ & $\begin{array}{l}\text { Normal (Ferric } \\
\text { chloride test } \\
\text { positive) }\end{array}$ \\
\hline $\begin{array}{l}\text { Urine dipstick } \\
\text { test**** }\end{array}$ & 1 to $4+$ & 1 to $4+$ & 1 to $4+$ & Normal & Normal & Normal \\
\hline Serum & Normal & $\begin{array}{c}\text { Pink (low } \\
\text { haptoglobin) }\end{array}$ & $\begin{array}{l}\text { Normal (increase } \\
\text { ofmyo- } \\
\text { globin,creatinine } \\
\text { kinase, and } \\
\text { liverenzymes } \\
\text { inrhabdomyolysis) }\end{array}$ & Icteric & Normal & Normal \\
\hline Muscle symptoms & No & No & Myalgias & No & $\begin{array}{l}\text { Abdominal } \\
\text { cramps. }\end{array}$ & $\begin{array}{l}\text { No (ochronosis } \\
\text { and arthritis) }\end{array}$ \\
\hline
\end{tabular}

${ }^{*}$ RBC red blood cells.

** Normal refers to white or yellow in color.

$* * *$ The sediment and supernatant urine examined after centrifugation.

**** Semiquantitative test (orthotolidine or peroxidase) detects heme peroxidase activity in RBC, hemoglobin or myoglobin with reported sensitivity of 91100\%. $(1+=5-10 \mathrm{RBC} / \mu \mathrm{L}, 4+=$ approx. $250 \mathrm{RBC} / \mu \mathrm{L})$.

Although rapid reduction of body temperature and repletion of body fluids remain the vital first priority in the treatment of HS, this together with vigorous intensive care management and vital supporting measures may result in patient survival and complete recovery. Nevertheless, to date little is known about the prognosis of patients with HS, and more data are needed to determine the most appropriate and effective management strategies for these cases.

\section{Acknowledgment}

The authors are indebted to Mr. Michael Bench for his assistance in the preparation of the paper.

\section{References}

[1] P. A. Gabow, W. D. Kaehny, and S. P. Kelleher, "The spectrum of rhabdomyolysis," Medicine, vol. 61, no. 3, pp. 141-152, 1982.

[2] R. L. Mehta, J. A. Kellum, S. V. Shah et al., "Acute Kidney Injury Network: report of an initiative to improve outcomes in acute kidney injury.", Critical Care, vol. 11, no. 2, article R31, 2007.

[3] G. Melli, V. Chaudhry, and D. R. Cornblath, "Rhabdomyolysis: an evaluation of 475 hospitalized patients," Medicine, vol. 84, no. 6, pp. 377-385, 2005.

[4] M. M. Ward, "Factors predictive of acute renal failure in rhabdomyolysis," Archives of Internal Medicine, vol. 148, no. 7, pp. 1553-1557, 1988.
[5] A. Bouchama and J. P. Knochel, "Medical progress: heat stroke," The New England Journal of Medicine, vol. 346, no. 25, pp. 1978-1988, 2002.

[6] J. P. Knochel and G. Reed, "Disorders of heat regulation," in Maxwell and Kleeman's Clinical Disorders of Fluid and Electrolytes Metabolism, R. G. Narins, Ed., pp. 1549-1590, McGraw-Hill, New York, NY, USA, 5th edition, 1994.

[7] G. H. Clowes Jr. and T. F. O'Donnell, "Heat stroke," The New England Journal of Medicine, vol. 291, no. 11, pp. 564-567, 1974.

[8] B. Misset, B. De Jonghe, S. Bastuji-Garin et al., "Mortality of patients with heatstroke admitted to intensive care units during the 2003 heat wave in France: a national multiplecenter risk-factor study," Critical Care Medicine, vol. 34, no. 4, pp. 1087-1092, 2006.

[9] F. LoVecchio, A. F. Pizon, C. Berrett, and A. Balls, "Outcomes after environmental hyperthermia," American Journal of Emergency Medicine, vol. 25, no. 4, pp. 442-444, 2007.

[10] P. Dennen, I. S. Douglas, and R. Anderson, "Acute kidney injury in the intensive care unit: an update and primer for the intensivist," Critical Care Medicine, vol. 38, no. 1, pp. 261-275, 2010.

[11] D. J. Buggy and A. W.A. Crossley, "Thermoregulation, mild perioperative hypothermia and post-anaesthetic shivering," British Journal of Anaesthesia, vol. 84, no. 5, pp. 615-628, 2000.

[12] J. E. Dematte, K. O’Mara, J. Buescher et al., "Near-fatal heat stroke during the 1995 heat wave in Chicago," Annals of Internal Medicine, vol. 129, no. 3, pp. 173-181, 1998.

[13] S. F. Raju, G. H. Robinson, and J. D. Bower, "The pathogenesis of acute renal failure in heat stroke," Southern Medical Journal, vol. 66 , no. 3, pp. 330-333, 1973. 
[14] W. H. Bagley, H. Yang, and K. H. Shah, "Rhabdomyolysis," Internal and Emergency Medicine, vol. 2, no. 3, pp. 210-218, 2007.

[15] S. G. Holt and K. P. Moore, "Pathogenesis and treatment of renal dysfunction in rhabdomyolysis," Intensive Care Medicine, vol. 27, no. 5, pp. 803-811, 2001.

[16] X. Bosch, E. Poch, and J. M. Grau, "Rhabdomyolysis and acute kidney injury," The New England Journal of Medicine, vol. 361, no. 1, pp. 62-72, 2009.

[17] J. Veenstra, W. M. Smit, R. T. Krediet, and L. Arisz, "Relationship between elevated creatine phosphokinase and the clinical spectrum of rhabdomyolysis," Nephrology Dialysis Transplantation, vol. 9, no. 6, pp. 637-641, 1994.

[18] A. R. de Meijer, B. G. Fikkers, M. H. De Keijzer, B. G. M. van Engelen, and J. P. H. Drenth, "Serum creatine kinase as predictor of clinical course in rhabdomyolysis: a 5-year intensive care survey," Intensive Care Medicine, vol. 29, no. 7, pp. 1121-1125, 2003.

[19] G. Woodrow, A. M. Brownjohn, and J. H. Turney, "The clinical and biochemical features of acute renal failure due to rhabdomyolysis," Renal Failure, vol. 17, no. 4, pp. 467-474, 1995.

[20] F. V. Schiødt and W. M. Lee, "Fulminant liver disease," Clinics in Liver Disease, vol. 7, no. 2, pp. 331-349, 2003.

[21] M. A. Pastor, F. Perez-Aguilar, V. Ortiz, D. Nicolas, and J. Berenguer, "Acute hepatitis due to heatstroke," Gastroenterología y Hepatología, vol. 22, no. 8, pp. 398-399, 1999.

[22] Y. Heled, M. Rav-Acha, Y. Shani, Y. Epstein, and D. S. Moran, "The "golden hour" for heatstroke treatment," Military Medicine, vol. 169, no. 3, pp. 184-186, 2004. 


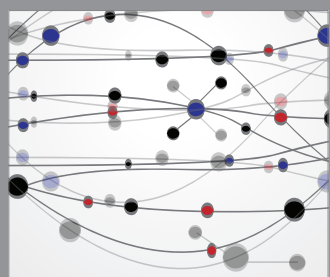

The Scientific World Journal
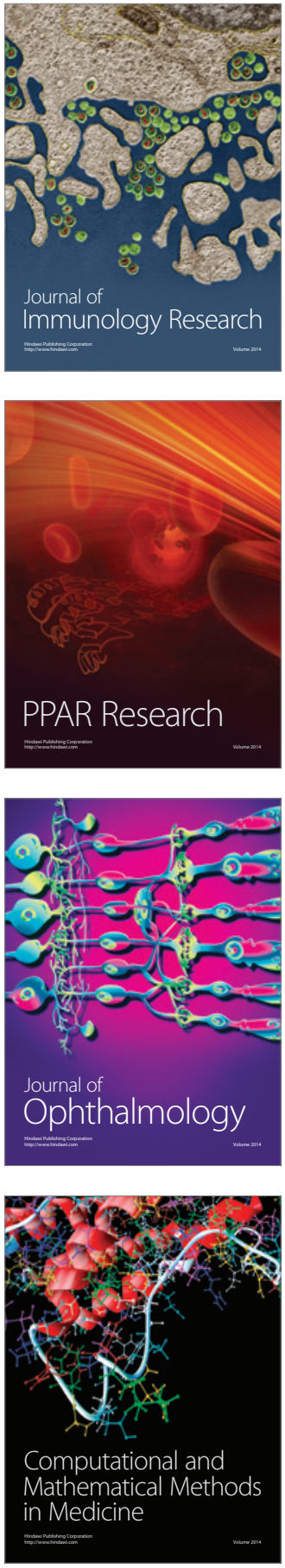

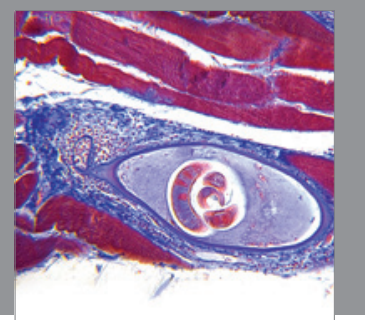

Gastroenterology

Research and Practice
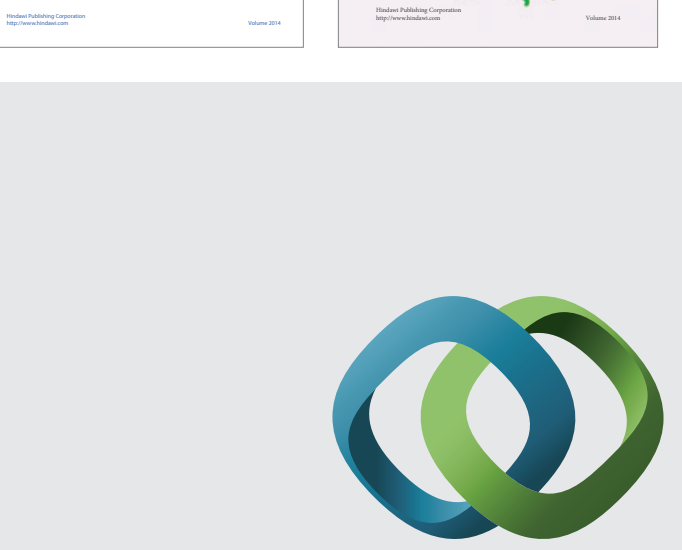

\section{Hindawi}

Submit your manuscripts at

http://www.hindawi.com
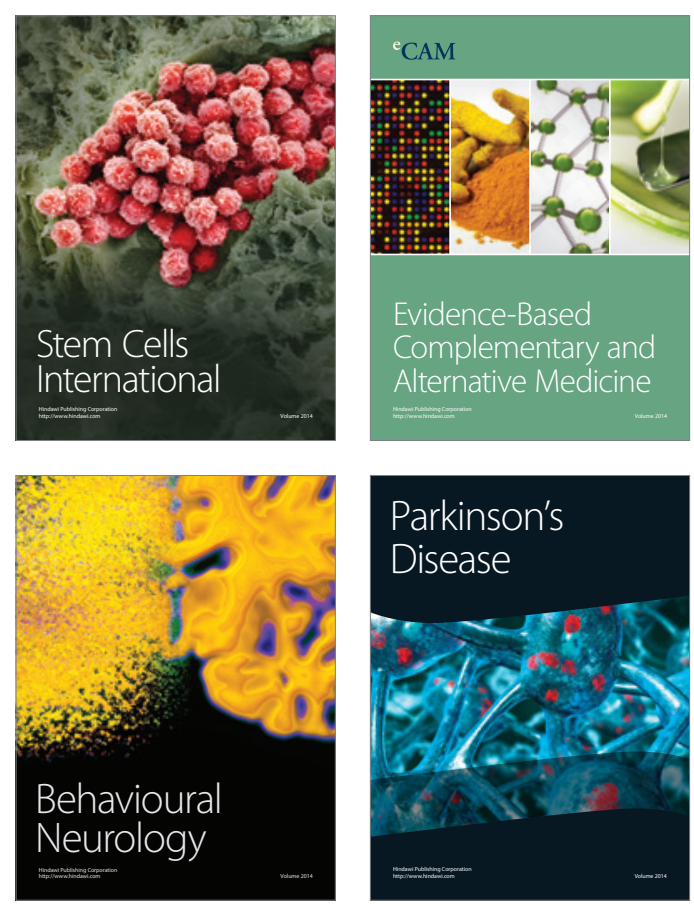

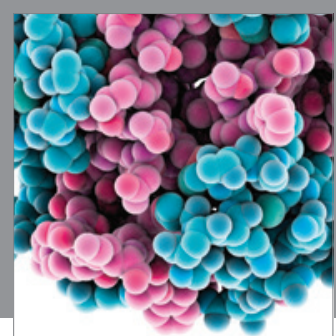

Journal of
Diabetes Research

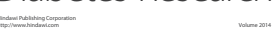

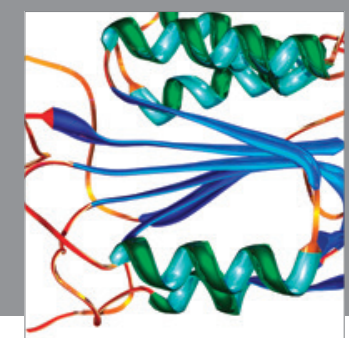

Disease Markers
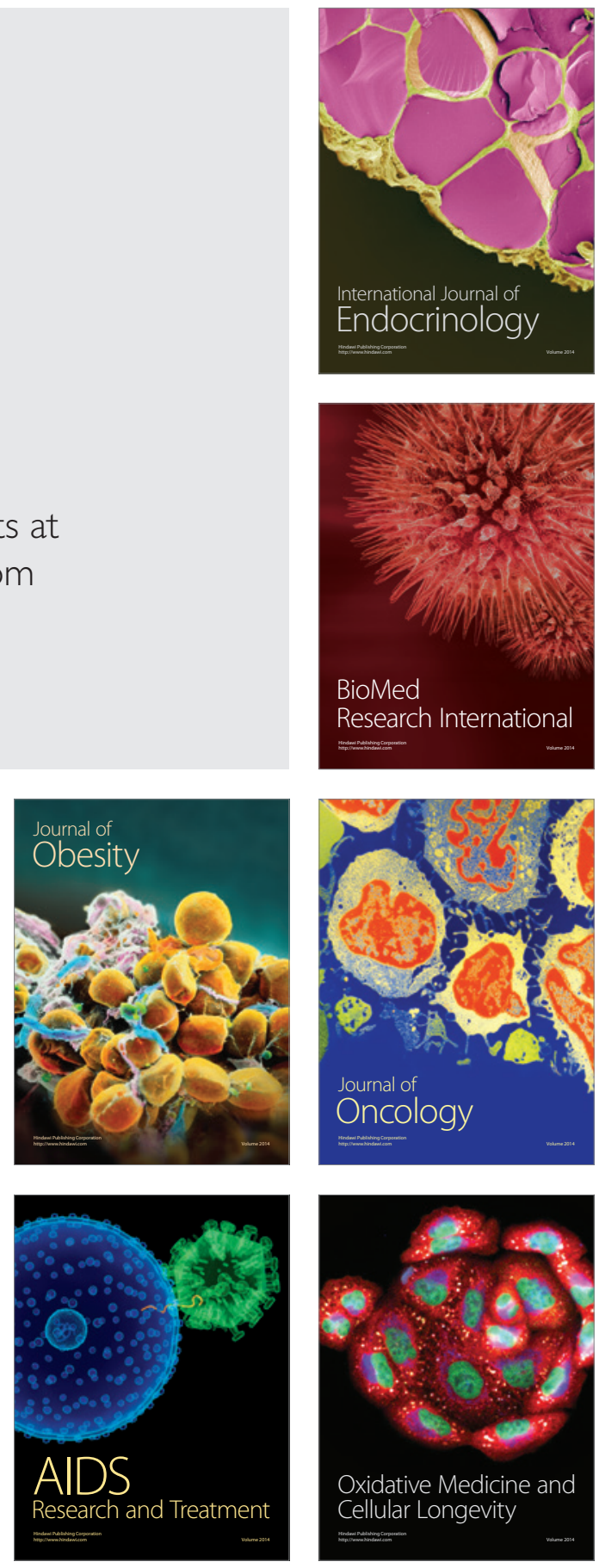